Mini-Review Artide

JOURNAL OF THE CAMEROON ACADEMY OF SCIENCES Vol. 14 No. 3 (JANUARY 2019)

\title{
The plant microbiome as a resource to increase crop productivity and soil resilience: A systems approach
}

Salme Timmusk ${ }^{1}$ and Claudio Zucca ${ }^{2}$

${ }^{1}$ D epartment of Forest Mycology and Plant Pathology, Swedish University of Agricultural Sciences, Uppsala, Sweden

${ }^{2}$ Soil Conservation \& Land Management Specialist, International Center for Agricultural Research in the Dry Areas (ICARDA)

*Corresponding Author: Department of Forest Mycology and Plant Pathology, Swedish University of Agricultural Sciences, P.O. Box 7026, SE-75007 Uppsala, Sweden salme.timmusk@ slu.se

\begin{abstract}
Climate change along with global population increase pose a challenge to worldwide crop

production and soil health. There is a need to intensify agricultural production in a sustainable manner and to find solutions to combat abiotic and biotic stress situations. Plant roots can be colonized by a variety of favorable species and genera that promote plant growth. A systems approach to integrating plant breeding and microbiome via applying novel molecular tools, screening technologies and precision phenotyping has the potential to advance the microbial reproducible application under natural conditions.
\end{abstract}

\section{Resume}

Le changement climatique ainsi que l'augmentation de la population mondiale posent un défi pour la production agricole mondiale et la santé des sols. Il est nécessaire d'intensifier durablement la production agricole et de trouver des solutions pour lutter contre les situations de stress abiotiques et biotiques. Les racines des plantes peuvent être colonisées par une variété d'espèces et de genres favorables qui favorisent la croissance des plantes. Une approche systémique d'intégration de la sélection végétale et du microbiome via l'application de nouveaux outils moléculaires, de technologies de criblage et d'un phénotypage de précision pourrait faire progresser l'application reproductible microbienne dans des conditions naturelles

Received: $12 / 09 / 2018$

Accepted: $27 /$ 12/ 2018

DO I: https:/ / dx.doi.org/ 10.4314/ jcas.v14i3.2

(C) The Authors. This work is licensed under the Creative Commons Attribution 4.0 International Licence. 
Introduction

Climate change has resulted in significant changes in weather pattern, precipitation distribution, and temperature and moisture fluctuations (FAO 2008). Extreme conditions caused by these changes bring about many unexpected and more frequent biotic and abiotic stresses (Bebber, Ramotowski et al. 2013; Bebber, Holmes et al. 2014; Trenberth, Dai et al. 2014; Wallace, Held et al. 2014), in particular, novel combinations of stress severities (Niinemets, Kahru et al. 2017). To feed the increasing world population, total crop production will need to be significantly increased, and from a reduced total area that is liable to more severe environmental stress conditions (Kennedy, Naeem et al. 2002; Tilman, Cassman et al. 2002; Foley, Ramankutty et al. 2011; OECD/FAO 2013; FAO 2014). Drought is expected to expand globally owing to increased evaporation and reduced rainfall or changes in the spatial and temporal distribution of rainfall (D ai 2012). This challenge is particularly acute in sub-Saharan Africa (SSA) and North Africa, as the dryland agriculture contributes significantly to its economy. In addition to decreased agricultural area, the countries face a major concern arising from soil erosion intensified by climate change. This not only reduces soil fertility but contributes to eutrophication of inland and offshore water bodies. Hence the situation calls for novel sustainable agricultural technologies (D ai 2012). It is clear that no single technology can meet all the challenges, or even adequately address a single challenge, such as drought or reduction in soil fertility. In order to reduce vulnerability of agricultural systems to climate change, the applied agricultural technologies should be environmentally friendly, ensure high productivity, and be suitable for farmers' adoption. These goals can be achieved via development and dissemination of innovative interdisciplinary technology combining holistic plant breeding with the native microflora/ microbiome (Timmusk, Behers et al. 2017; Timmusk and Behers 2018).

It is known that plant microbiomes evolve with the host and significantly contribute to environmental adaptation (Timmusk, Paalme et al. 2011; Dai 2012; Timmusk and Behers 2012; Timmusk, Timmusk et al. 2013). D ryland soils have always been affected by several constraints. However, over the millennia dryland communities developed adaptation strategies that enabled them not only to cope with scarcity of water and natural resources, but to encourage the development of flourishing civilizations. Think of the Nabateans in southern Jordan. The recent rapid demographic and socio-economic changes led to intensification processes that were not sustainable, causing extensive soil degradation and undermining the soil capacity to perform its productive and ecological functions, including buffering the impacts of climate variability. In order to reestablish the balance, native microbiome application technologies have to be developed (Timmusk, Behers et al. 2017). Despite their centrality to life on Earth, we apply very little of the native microbiome potential to stressed environments. D NA sequencing technologies have enabled a new view of the ubiquity and diversity of microorganisms, their functions and community dynamics (Alivisatos, Blaser et al. 2015; Hultman, Waldrop et al. 2015; Xu, Naylor et al. 2018). Therefore, manipulation of the native microbiome associated with crops represents a promising strategy for addressing many of the challenges climate change poses to soil health as well as to agricultural productivity.

\section{Water productivity breeding}

Soil water and nutrient availability are the biggest challenges of agricultural production under climate change. Agriculture is the largest water consumer as 
well as a major source for eutrophication. Intensifying agriculture via expanding to new areas is a limited prospect as it requires more water. Water productivity (WP) is the net return for the water use or the ratio of biomass with the economic value (edible yield) versus the amount of water transpired. Improved nutrient content and WP can be accomplished by breeding water/ nutrient - efficient crops. The International Center for Agricultural Research in the Dry Areas (ICARDA) along with internationally recognized academic breeding centers has established a solid platform for WP breeding (Dwivedi, Britt et al. 2015; Ortiz 2015; Lobos, Camargo et al. 2017; Valdiani, Talei et al. 2017). Selected genotypes are better suited to cope with environmental fluctuations and extremes such as drought and heat spells. Whole-genome prediction models estimate all marker effects in all loci and capture small quantitative trait loci (QTL) mapping effects are applied have resulted in impressive advances and became routine in agricultural breeding (D wivedi, Britt et al. 2015; Ortiz 2015; Lobos, Camargo et al. 2017; Valdiani, Talei et al. 2017). At the phenotype level, improved agricultural techniques and novel highthroughput selection systems are being developed to enable rapid pre-field screening for specific traits. Yet greater unpredictability of weather conditions under climate change makes it clear that plant breeding alone is not able to meet challenges and calls for strategies completing phenotypic plasticity and adaptability without curtailing yield potential.

\section{Plant growth-promoting rhizobacteria}

The soil surrounding plant roots is one of the main sources of plant growth promoting rhizobacteria (PG PR) that have metabolic capabilities for growth promotion and protection of different crops from abiotic and biotic stress (Timmusk 2013; Timmusk, El Daim et al. 2014; Timmusk, Kim et al. 2015;
Timmusk, Seisenbaeva et al. 2018). The very first report on enhancement of plant drought stress tolerance by rhizosphere bacteria was published in 1999 (Timmusk and Wagner 1999). Later, the discovery was updated with the principally new approach using harsh environment bacteria which have evolved together with the plant roots for thousands of years. Several systems in plants and bacteria have developed in the harsh environments that trigger the available resources and initiate the metabolic growth that is needed in different stress situations in agriculture under climate change. The studies reveal five times greater survival and 78\% higher biomass from inoculated plants under drought stress (Timmusk 2013; Timmusk, El D aim et al. 2014; Timmusk, Kim et al. 2015). This is due to the bacterial ability to protect against abiotic stress as well as facilitate nutrient acquisition. As an example the coalescence and self-assembly of $\mathrm{TiO} 2$ nanoparticles on the surface of cell membranes leads to formation of dense and stable biofilms able to improve the survival and function of rhizobacteria. This enhances bacterial attachment to the root and plant biomass (Fig. 1) (Palmqvist, Bejai et al. 2015; Timmusk, Seisenbaeva et al. 2018). In order to be able to reveal the mechanism of action and monitor the fate performance of the strains, strategies for the strains genetic manipulation have been developed and genomes sequenced (Kim and Timmusk 2013). Although the exact mechanisms of plant drought stress tolerance enhancement by the bacteria varies dependent on seedlings age and mode of inoculation, the bacterial biofilm formation on plant roots forms ground to other mechanisms (Timmusk and Wagner 1999; Mayak, Tirosh et al. 2004; Conrath, Beckers et al. 2006; Glick, Todorovic et al. 2007; Dimkpa, Weinand et al. 2009; Sun, Cheng et al. 2009; Yang, Kloepper et al. 2009; Hao, Charles et al. 2011; Timmusk and Nevo 2011; Stearns, Woody et al. 2012; Kim, Glick et al. 2013; Timmusk 2013; 

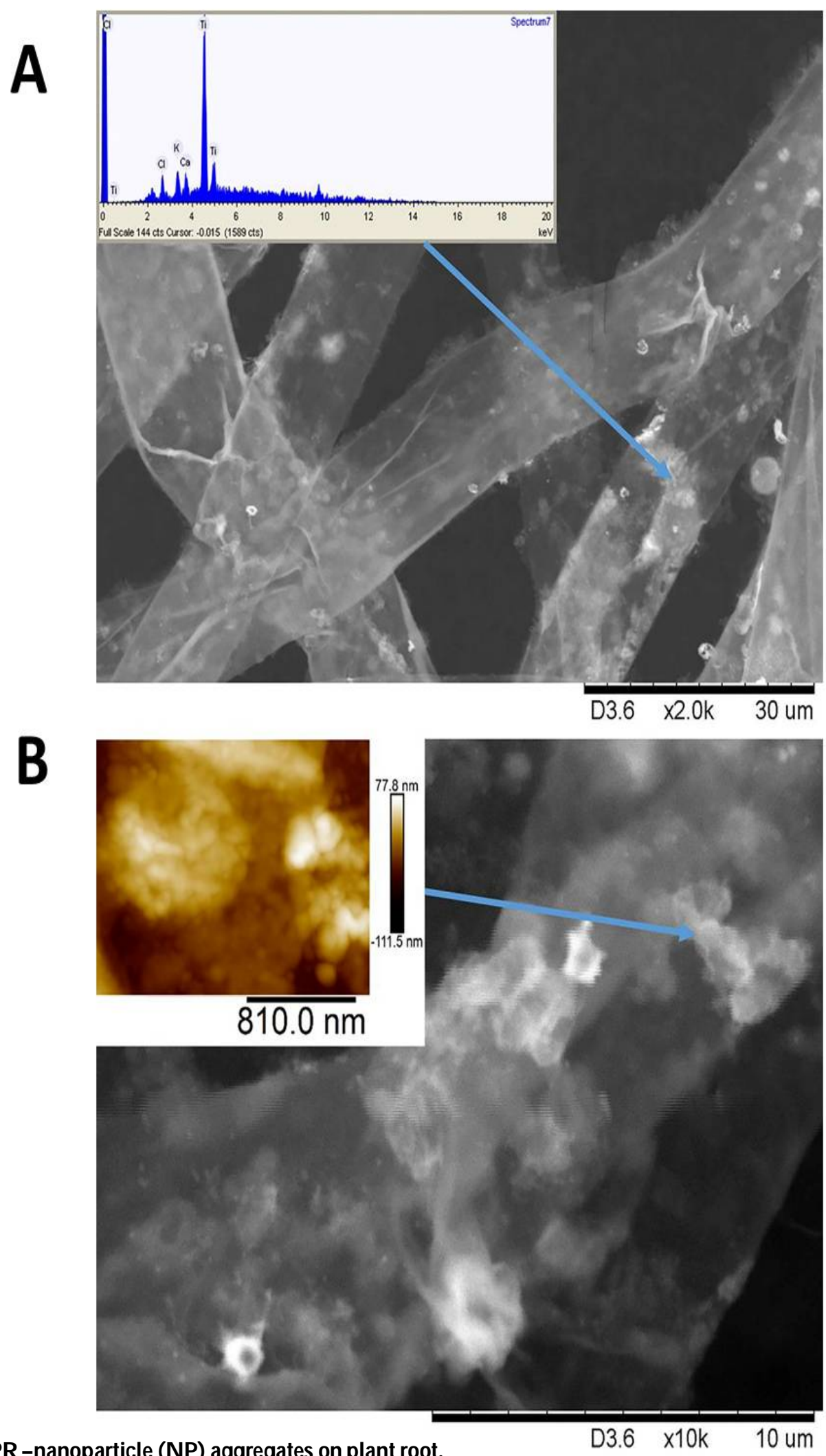

Figure 1 PGPR - nanoparticle (N P) aggregates on plant not.

Typical scanning electron microscopy- energy-dispersiveX-ray spectroscopy (EDS) images of PGPR cells grown with NPs for 24 hours on plant root after 6 hours of inoculation (A). and the characteristic aggregate sizes of 50-60 nm (B). Timmusk et al 2018 Nature, SciRep 10.1038/ s41598-017-18939-x 
Timmusk, Copolovici et al. 2018). The dense biofilm matrix limits diffusion of biologically active compounds secreted by bacteria including macro and microelement sequestration from soil. In addition, biofilm formation on root hair substantially improves root-to-soil contact $(\mathrm{Yu}$, Lor et al. 2015), so that biofilm formation per se, importantly contributes to improving plant nutrition. An extracellular matrix formed by bacterial biofilm can provide an almost infinite range of macromolecules beneficial for plant development and growth. Biofilms contain sugars and oligo- and polysaccharides that can play various roles in bacteria-plant interactions, e.g. improving water availability in root medium. The water retention capacity of some polysaccharides can exceed several-fold their mass and even small amounts of the sugars in the biofilm can facilitate maintenance of the hydrated micro-environment (Timmusk, Paalme et al. 2011; Timmusk 2013; Timmusk, Copolovici et al. 2018). O ur results demonstrate that the natural soil particles significantly contribute stably attaching PGPRs to plant roots and can be efficiently used for PG PR formulation (Fig. 1). The bacterial layers can be used as a tool for rational design of holobionts in food security programs. Future directions, should aim for combined phenotypic platform i.e bridging the genotype- phenotype gap by improving quantitative and automated selection and screening methods that focus on whole-plant physiology and quality traits.

\section{Conclusion}

In order to achieve substantial progress in agriculture and meet the challenges of the 21st century, adoption of systems agriculture is required. This means an integrated approach of plant breeding and microbiome via applying novel molecular tools, screening technologies and precision phenotyping. By manipulating interactions at the root-soil-microbe interface, we may reduce agricultural pesticide, fertilizer, and water use, enrich marginal land, and rehabilitate degraded soils. Hence, a concept integrating plant breeding with the microbiome and rational management of microbial communities has great potential for sustainable precision agriculture.

\section{References:}

Alivisatos, A. P., M. J. Blaser, et al. (2015). "MICROBIOME. A unified initiative to harness Earth's microbiomes." Science 350(6260): 507 508.

Bebber, D. P., T. Holmes, et al. (2014). "Economic and physical determinants of the global distributions of crop pests and pathogens." New Phytol 202(3): 901-910.

Bebber, D. P., M. A. T. Ramotowski, et al. (2013). "Crop pests and pathogens move polewards in a warming world." Nature Climate Change 3(11): 985-988.

Conrath, U., G. J. Beckers, et al. (2006). "Priming: getting ready for battle." Mol Plant Microbe Interact 19(10): 1062-1071.

Dai, A. (2012). "Increasing drought under global warming in observations and models." Nat Clim Change 3: 52-58.

Dimkpa, C., T. Weinand, et al. (2009). "Plant rhizobacteria interactions alleviate abiotic stress conditions." Plant Cell Environ 32(12): 1682 1694.

D wivedi, S. L., A. B. Britt, et al. (2015). "Haploids: Constraints and opportunities in plant breeding." Biotechnol Adv 33(6 Pt 1): 812-829.

FAO (2014)." (Food and Agriculture O rganization of the United States)." FAO STAT online data United Nations, Rome.

Foley, J. A., N. Ramankutty, et al. (2011).

"Solutions for a cultivated planet." Nature 
478(7369): 337-342.

Glick, B., B. Todorovic, et al. (2007). "Promotion of plant growth by bacterial ACC deaminase." Crit Rev Plant Sci 26: 227-242.

Hao, Y., T. C. Charles, et al. (2011). "ACC deaminase activity in avirulent Agrobacterium tumefaciens D3." Can J Microbiol 57(4): 278 286.

Hultman, J., M. P. Waldrop, et al. (2015). "Multi omics of permafrost, active layer and thermokarst bog soil microbiomes." Nature 521(7551): 208 212.

Kennedy, T. A., S. Naeem, et al. (2002). "Biodiversity as a barrier to ecological invasion." Nature 417(6889): 636-638.

Kim, S.-B. and S. Timmusk (2013). "A simplified method for Paenibaillus polymyxa gene knockout and insertional screening." PLoSONE 10.1371 journal.pone.0068092: 1-6.

Kim, Y.-C., B. Glick, et al. (2013). Enhancement of plant drought tolerance by microbes. Plant responses to drought stress. R. Aroca. Berlin, Springer Verlag: 383-413.

Lobos, G. A., A. V. Camargo, et al. (2017). "Editorial: Plant Phenotyping and Phenomics for Plant Breeding." Front Plant Sci 8: 2181.

Mayak, S., T. Tirosh, et al. (2004). "Plant growth promoting bacteria confer resistance in tomato plants to salt stress." Plant Physiol Biochem 42(6): 565-572.

Niinemets, Ü., A. Kahru, et al. (2017). “ Interacting environmental and chemical sRegional Environmental Change " tresses under global change in temperate aquatic ecosystems: stress responses, adaptation, and scaling 17: 2061-2077.
OECD/FAO (2013). OECD-FAO Agricultural O utlook 2013-2022, OECD Publishing and FAO.

Ortiz, R. (2015). Plant breeding in the omics era. NY, Springer.

Palmqvist, N. G., S. Bejai, et al. (2015). "Nano titania aided clustering and adhesion of beneficial bacteria to plant roots to enhance crop growth and

stress management." Sci Rep 5: 1-10

Stearns, J. C., O. Z. Woody, et al. (2012). "Effects of bacterial ACC deaminase on Brassica napus gene expression." Mol Plant Microbe Interact.

Sun, Y., Z. Cheng, et al. (2009). "The presence of

a 1-aminocyclopropane-1-carboxylate (ACC) deaminase deletion mutation alters the physiology of the endophytic plant growth-promoting bacterium Burkhddaria phytofimans PsJN." FEMS Microbiol Lett 296(1): 131-136.

Tilman, D., K. G. Cassman, et al. (2002). "Agricultural sustainability and intensive production practices." Nature 418(6898): 671 677.

Timmusk, S. (2013). "Rhizobacteria and uses thereof PCT/ SE2013/ 050898.” PCT ArosPatentAB(14423175 PCT/ SE 2013 050898).

Timmusk, S. and L. Behers (2012).

"Rhizobacterial application for sustainable water management on the areas of limited water resources." Irrigation and D rainage Systems Engineering 12(2-4): 1-4 doi: 10.4172/ 2168-9768.1000e4111.

Timmusk, S. and L. Behers (2018). "Plant roots: Integrating plant microbiome for crop impovement." Front Plant Sci in revision. Timmusk, S., L. Behers, et al. (2017). "Perspectives and challenges for microbial 
application for crop improvement “ Front. Plant Sci.: 1-10.

Timmusk, S., D. Copolovici, et al. (2018). "Paenibacillus polymyxa biofilm polysaccharides antagonise Fusanium gamineanmD 0 I:10.1038 s41598-018-37718-w." Sci. rep. .

Timmusk, S., I. El D aim, et al. (2014). "D rought tolerance of wheat improved by rhizosphere bacteria from harsh environments: enhanced biomass production and reduced emissions of stress volatiles." PloS ONE 1-13

Timmusk, S., S. Kim, et al. (2015). "Sfp- type PPTase inactivation promotes bacterial biofilm formation and ability to enhance plant drought tolerance " Frontiers in Microbiol: 1-13.

Timmusk, S. and E. Nevo (2011). Plant root associated biofilms. Bacteria in agrobiology (vol 3) : Plant nutrient management. D. K.

Maheshwari. Berlin, Springer Verlag: 285-300.

Timmusk, S., V. Paalme, et al. (2011). "Bacterial distribution in the rhizosphere of wild barley under contrasting microclimates." PLoS O ne 6(3): 1-8.

Timmusk, S., G. A. Seisenbaeva, et al. (2018). "Titania (TiO2) nanoparticles enhance the performance of growth-promoting rhizobacteria D O I : 10.1038/ s41598-017-18939-x." Nature Sci Rep.

Timmusk, S., K. Timmusk, et al. (2013). "Rhizobacterial plant drought stress tolerance enhancement." J. Food Security 11: 10-16.

Timmusk, S. and E. G. Wagner (1999). “The plant growth-promoting rhizobacterium Paribaillus pdymyxa induces changes in Arabidqpis thaliana gene expression: a possible connection between biotic and abiotic stress responses." Mol Plant Microbe Interact 12(11): 951-959.

Trenberth, K. E., A. G. D ai, et al. (2014). “Global warming and changes in drought." Nature Climate Change 4(1): 17-22.

Valdiani, A., D. Talei, et al. (2017). "G enoproteomics-assisted improvement of Andrographis paniculata: toward a promising molecular and conventional breeding platform for autogamous plants affecting the pharmaceutical industry." Crit Rev Biotechnol 37(6): 803-816.

Wallace, J. M., I. M. Held, et al. (2014). "Global warming and winter weather." Science 343(6172): 729-730.

Xu, L., D. Naylor, et al. (2018). "D rought delays development of the sorghum root microbiome and

enriches for monoderm bacteria." Proc Natl Acad Sci U S A.

Yang, J., J. W. Kloepper, et al. (2009).

"Rhizosphere bacteria help plants tolerate abiotic stress." Trends Plant Sci 14(1): 1-4.

Yu, P., P. Lor, et al. (2015). "Quantitative evaluation of IAA conjugate pools in Arabidopsis thaliana." Planta 241(2): 539-548. 